\title{
The Study of New Model for Urban Governance in Guangzhou
}

\author{
Jie Qu \\ School of Public Administration and Emergency Management, Jinan University, Guangzhou, China \\ Email: 2517676534@qq.com
}

How to cite this paper: Qu, J. (2017) The Study of New Model for Urban Governance in Guangzhou. Open Journal of Social Sciences, 5, 7-16.

https://doi.org/10.4236/jss.2017.52002

Received: January 6, 2017

Accepted: January 22, 2017

Published: January 25, 2017

Copyright $\odot 2017$ by author and Scientific Research Publishing Inc. This work is licensed under the Creative Commons Attribution International License (CC BY 4.0).

http://creativecommons.org/licenses/by/4.0/

\begin{abstract}
With the development of China's economy and society, citizens have strong will to participate in urban governance, but the failure of public participation has occurred occasionally. As one of the central cities in China, Guangzhou has taken the lead in embarking urban governance reformation, and set up a public advisory committee among the people's livelihood projects to coordinate the relationship among all interests' parties. This diversified participatory governance model has achieved significant results in practice, but also encountered new resistance. The paper explores the reasons why the Public Advisory Committee (CPA) model is hindered in other livelihood projects and puts forward some countermeasures to optimize the urban governance reform in Guangzhou.
\end{abstract}

\section{Keywords}

Urban Governance, Public Participation, The Public Advisory Committee

\section{Introduction}

China is in the stage of rapid urbanization, the urban public problems such as problems about transportation, housing and environmental protection etc. happen frequently, and the increasingly diversified demands for public interest make the problem more complicated. Obviously, the traditional urban governance model in which government is dominant has been powerless, and expanding public participation as well as endeavoring to public opinion has become the inevitable choice for urban governance reform (Sheng, 2012) [1]. However, only a small part of the positive people can use limited channels such as network, media etc. to express their appeals successfully in reality, leading to a minority of views abducting most of the public opinion. Therefore, integrating social resources extensively and realizing effective interaction between the gov- 
ernment and the civil have become the only way to resolve the current urban management plight. Based on this trend, the Guangzhou government began to consider the establishment of public participation platform to explore the transform in governance model. The implementation of this concept has achieved actual results in the comprehensive renovation works at Tongdewei area, Guangzhou City in 2012. By the leading of the Guangzhou government, the “Tongdewei Comprehensive Renovation Work Advisory Committee" was established, as the deliberative institution to coordinate relationships among the interested parties. The "Advisory Committee" collects resident issues and opinions extensively, and feed them back to the government uniformly; government departments are targeted to hold research meeting and public hearings to conduct democratic deliberations, and finally make decisions.

In the view of the governance effect, the "Tongdewei" case is successful, and the key factor lies in the "Tongdewei Advisory Committee" playing an effective role. Since then, the Public Advisory Committee began to be promoted in other livelihood projects in Guangzhou City. So far, there are more than ten public consultation and supervision committees set up in Guangzhou. This kind of urban governance mode which sets up deliberative institution in livelihood projects to coordinate the relationship between the government and the public is called the "Public Advisory Committee mode" (Yang, Zhao, \& Hu, 2015) [2]. It can be said that the "Public Advisory Committee model" has already meet with preliminary success in Guangzhou, which is the important criterion to decide Guangzhou's urban governance reform being in the forefront of the country. We should continue to explore the "Public Consultative Committee mode", find out the deficiencies in the process of promotion, overcome the shortcomings, improve and enrich its connotation further, and promote the new reform of urban governance in Guangzhou. This paper discusses a new model of urban governance in Guangzhou, which offers the possibility to improve the effectiveness of urban governance and to enhance the effectiveness of public participation. The paper is structured in sections that discuss the following: the connotation of the new model of urban governance, the new model to promote the situation and problems, the way to solve these problems, and a conclusion.

\section{Analysis on Typical Case in the Process of Promotion of the Public Advisory Committee}

\subsection{Establishment of the Jinshazhou Public Advisory Committee}

Guangzhou's Jinshazhou area is located in the border region of Guangzhou City and Foshan City, and more than 100,000 residents are gathered here, who has long been suffering from the backward infrastructure. Reference to the successful experience of Tongdewei's governance, the "Public Supporting Facilities Advisory Committee" was set up at Jinshazhou area in April, 2013; members are divided into three parts, including social care person, Jinshazhou residents and local business representatives. Its daily work mode is that the chairman and secretary- 
general of the Public Advisory Committee are responsible for deliberating and dealing with not important issues; while meeting the important things, all members of the Public Advisory Committee are convened to have a meeting, and meanwhile the relevant functional government departments dispatch representatives to attend the meeting, get the situation and make a feedback. When the Jinshazhou Public Advisory Committee was established for less than a year, the Control Detailed Planning in Jinshazhou Area was unanimously approved in Guangzhou City Planning Commission, and gained great satisfaction from the residents of Jinshazhou area. Such success is inseparable from the field research, exchanging opinion and asking for opinion between the Public Advisory Committee and the planning department. The establishment of the Public Advisory Committee has promoted the completion of the rectification work in Jinshazhou area.

\subsection{Project of Widening the Guangzhou Bridge}

Influenced by procrastination of the Guangzhou Baiyun Mountain tunnel due to public opposition, the Guangzhou City Construction Committee decided to change the existing decision-making process of urban construction project, and establish the Public Advisory Committee for important urban construction projects as a platform to express public opinion. There are a total of 25 members in the Public Advisory Committee for important urban construction projects, including four NPC members, four CPPCC members, seven experts and scholars as well as ten representatives of the public. Five of them are stakeholders. After the establishment of the Public Advisory Committee for important urban construction projects, the first discussion topic is the project of widening the Guangzhou Bridge. In the meeting discussing whether the Guangzhou Bridge should be broaden, 20 present permanent members of the Public Advisory Committee voted for project of broadening bridge and the development scheme, passing with 12 concurring vote and 8 dissenting vote, but three of the five relevant stakeholders voiced opposition. The validity and fairness of the voting results have attracted extensive discussion and controversy of the public and media. First of all, in the urban governance, stakeholders have directly related interests, and should be the representative of having most right to speak. The proportion of stakeholders in the Committee is relatively lower, and the voting results are not representative. Secondly, this minority-majority vote cannot reflect the needs of the minorities. So the government should be aware of the importance and necessity of decision-making through consultation rather than voting. The establishment of other following advisory committees also should learn from the experience. When the Advisory Committee is established, the proportion of stakeholders should be appropriately expanded, and the members selected by the government of the Public Advisory Committee should be discarded, replaced by public elections, lottery, recommending by public elections, self-recommendation and other means to elect representatives.

\subsection{Temporary Replacement of the BRT Project Issues}

At the meeting of the Public Advisory Committee of Guangzhou Urban Con- 
struction, BRT project issues was temporarily replaced, which encountered dissatisfaction and wide denouncement from members of the Public Advisory Committee. According to the original plan, the Public Advisory Committee of Guangzhou Urban Construction originally planned to discuss the eight sets of alternative offer of the second BRT submitted by the Guangzhou Transportation Commission. However, before the meeting, members of the Committee and the media suddenly received an informing message from the news spokesman of the Public Advisory Committee of Guangzhou Urban Construction, saying that because the materials which the Guangzhou Transportation Commission had prepared was inadequate, BRT issues would be postponed and discussed issues was changed to the work summary in 2013 as well as work outlook in 2014 for the Public Advisory Committee. The choice of discussed issues determines the initiative of the Committee from the source. As a civilian oversight institution, the Public Advisory Committee lacks independence and autonomy. The discussed issues are selected by the government, so that "issues that are not conducive to government's decision-making cannot be discussed in the Public Advisory Committee, and opinions that are unfavorable to its default position cannot be produced". The temporary replacement of the issue has decided by the government in advance, and the Public Advisory Committee is just acting as a form.

\subsection{Overthrow and Re-Discussion about Donghaochong Landscape Scheme}

After the government had decided to start the comprehensive renovation project for the center-north section of the Donghaochong, the Public Advisory Committee of the Donghaochong was established by the leading of the Urban Construction Environment and Resources Protection Committee of the People's Congress Standing Committee at Yuexiu district, Guangzhou. This kind of process resulted in that the limited scope of the discussion left to the Public Advisory Committee of the Donghaochong was limited to landscape design and how to reduce the number of dissenting residents. So the space for the public to participate in the discussion was relatively small. The Public Advisory Committee of the Donghaochong discussed the construction program of the second phase of the landscape released by the Bureau of Parks and Woods for many times, and The Public Advisory Committee urged the designing institute to optimize the design program of landscape for it costed too much and the design program of landscape was too cumbersome. Subsequently, at the seventh plenary meeting of the Public Advisory Committee for comprehensive regulation project of the center-north section of the Donghaochong, constructing and optimizing plan for Phase II Landscape of the Donghaochong was denied once again. The Public Advisory Committee of the Donghaochong considered that the landscape construction scheme was not the views of the Committee from beginning to end and should be discussed by the Public Advisory Committee and the public from the outset to put forward scheme. The meeting finally agreed that the Public Advisory Committee and construction unit invited the experts, 
scholars as well as social elites to discuss the design scheme of Phase II Landscape of the Donghaochong, in order to complement the lack of professional knowledge and experience of the members of the Public Advisory Committee (Yang, Zhao, \& Hu, 2015) [2]. This is conducive for the introduction of public participation from the source, so that citizen participation can be integrated into every aspect of the project proposal, demonstration and decision-making.

\section{Analysis on the Cause of Promotion of the "Public Advisory Committee Model" Being Obstructed}

Although the Tongdewei Public Advisory Committee as a promotional example is successful, the Tongdewei Public Advisory Committee is a new thing after all, which has met a lot of problems in the actual promotion. And many of the public advisory committees were questioned for they cannot exert required effectiveness. While the Public Advisory Committee as a public organization, we can analyze its shortcomings and deficiencies from the perspective of internal and external factors.

\subsection{Internal Factors: The Lack of Independence and the Imperfect Mechanism}

\subsubsection{Lack of Independence}

The lack of independence is one of the main problems facing by the Public Advisory Committee. As the Guangzhou Public Advisory Committee was established under the support of the municipal government, it has a strong official background; it would also be affected by the government from all aspects in actual operation and lack of sufficient independence, mainly for the following aspects:

First, the composition of the staff is led by the government and the behalf for public interest is inadequate. In accordance with the requirements of the relevant system, the members of the Public Advisory Committee are composed of representatives of the National People's Congress, experts, scholars and representatives of residents. However, it is noteworthy that the members elected by the local residents to represent the public opinion are in the lower proportion of members, experts, scholars and representatives of the National People's Congress recommended by the government has relatively high ratio. In essence, the situation of "input elite inside, internal elite compromise for politics in decision-making process" is formed $(\mathrm{Hu}, 1998)$ [3]. This has led to that members of the Public Advisory Committee become the "voice tube" of the government and simply assist the government in making the public responsive to calls and decisions, but ignoring the appeal of stakeholders, so it is biased.

Second, the funding comes from the Government, so its finance lacks freedom. The Public Advisory Committee stresses its commonweal, and all its members have "Lei Feng" volunteer service, no wages and other labor subsidies, so there is no conflict of interest between members. The Government has also advocated such commonweal participation in political affairs. Therefore, in or- 
der to support the Public Advisory Committee and encourage its initiative, relevant departments provide funds for the Public Advisory Committee. But in this way, the Committee is financially dependent on the relevant departments, and lack of economic independence. With economic independence, the independence of the operation also cannot be guaranteed.

Third, the setting of topics for discussion is decided by the Government, so the initiative of the Advisory Committee is lost. The organizational structure and the financial resources of the Public Advisory Committee have made it difficult to achieve its own functions, and the loss of the initiative of topics for discussion also narrows the discourse space of the Committee. Although the relevant provisions stipulate that the Public Advisory Committee need to be set up in discussing major livelihood projects, however the definition "significant livelihood projects" is fuzzy, resulting in that what kind of projects need to set up the Advisory Committee is decided by the government. Therefore, the setting of the Public Advisory Committee is not up to the public themselves. Instead, when the relevant government departments need the help of the Public Advisory Committee, they are set up after the project is established. Based on this "need relationship", the issues of the Public Advisory Committee are often formulated by the relevant government departments, so that space of public participation in the discussion is narrower. On one hand, the narrowing of the scope of participation has hindered the enthusiasm of public participation. On the other hand, it make the public participation is not effective enough, so that public participation is absent in the important stage of public policy-making.

\subsubsection{Mechanism Is Imperfect and Lack Institutional Framework}

The inadequacy of the functioning mechanism of the Committee is another important internal cause of the obstruction in promoting the Committee.

First, as the typical case for Committee, the reason why the public orderly and extensively participated in the process of Tongdewei area's renovation, is largely due to the step-by-step leadership by government departments and the leader members of the Advisory Committee, rather than institutionalized advance. Compared with the success of regional governance, the operation of the Tongdewei Public Advisory Committee relies more on the autonomy of organization members and the personal prestige of organizational leaders, and an operationalized and standardized charter is not formed. And there is a certain degree of randomness in the consultation of citizens' opinions and supervision as well as participation in public decision-making etc. In the process of copying the model of lacking normalization, inherent problems are bound to repeated or even enlarged (Wei, 2003) [4]. This lack of the critical operational mechanisms has led to the loss of the effectiveness of the work of the Committee.

Second, because the decision-making model and stipulation on proportion of voting through are lacking in the rules of procedure, the decisions made by the Committee lack of rationality and legitimacy. Generally, the agendas of the Committee are sponsored by the leader and freely discussed just like salon rather 
than formal meeting. As a result, members often express their views in the discussion but it is difficult to seek common ground while reserving differences. Finally, the leader and a number of core members can only be re-negotiated, determined by the individual subjective wishes. One the one hand this kind of decision-making model is not necessarily representative of all members, on the other hand, it may be caused the Committee could not represent the interests of the public will. Obviously, the above situations lead to the failure of decisionmaking.

Third, there is a lack of restraint for members of the Commission, so less acting or nonfeasance occurs now and then. The arbitrary nature of the work of the members of the Committee make it difficult for the Committee to make decisions and the lack of consensus among the members of the Advisory Committee results in a decline in the authority of the Public Advisory Committee, and then results in a diminished voice of the Committee. Finally the Committee cannot represent public appeal and willingness, so public participation is difficult to function efficiently.

\subsection{External Factors: Decreased Public Willingness to Participate and Decreased Media Attention}

\subsubsection{Public Willingness to Participate Decreases}

In the case of "Tongdewei", the Public Advisory Committee of the Tongdewei and the relevant government departments put a lot of energy and cost in the interaction with the public, and the public around the Tongdewei area are also very concerned about the comprehensive rectification work, so the people have strong willingness to participate and the effect is better. But in the promotion process of the Public Advisory Committee, on the one hand considering the time and cost, the Public Advisory Committee and the relevant government departments do not communicate deeply and extensively with the stakeholders; on the other hand, because public representatives of participating in the Committee are limited, and they cannot completely represent the views of the public, so the opinions of the public representatives become insignificant and lacking substantial effect, resulting in that public's willingness to participate in the work of the Committee is reduced and people lost confidence to the work of the Committee. In the meantime, the government leads the agenda of the Public Advisory Committee, which can further lead public attitudes and behavior through the Public Advisory Committee, so as to enable people to accept and obey the government's decision, rather than really expressing their views. This kind of paternalistic absolute authority existing in government relevant department is aimed at regulating and controlling public participation (Amstein, 1969) [5]. In this case, the public participation is more like a gimmick, and whether the people's

representatives or the general public, will consider the Commission lacking substantive function, so the willingness to participate is difficult to be improved.

\subsubsection{Decline of Media Attention}

In today's environment of increasingly open and well-developed information, 
the media public opinion is an important tool for the people to monitor the government and participate in governance. And in turn, the media also have a great guiding effect on the people, and the guiding role played by the news media cannot be underestimated in promoting the civic participation (Miller, Goldenberg, \& Erbring, 1979) [6]. The decline of media attention is also an important reason for promotion of the Public Advisory Committee meeting "coldness". As a successful case, the Tongdewai Public Advisory Committee's operation is inseparable from promotion of the "Star Committee member" Han Zhipeng. To investigate the status of the Tongdewei, Han Zhipeng moved into Tongdewei alone and lived for two years. His personal appeal, acting style and extraordinary research story are excellent news material, therefore the media had high attention for the Tongdewei. As a director of the Public Advisory Committee, such a unique and distinctive elite color is extremely accidental, and it is difficult to be copied to other public advisory committees. So the media attention to the other public advisory committees is far less than the Tongdewei. This also shows that the successful promotion of the Committee has a high demand for the personal quality of the committee members, especially the director of the committee. Secondly, as the pilot project of promoting participatory urban governance in Guangzhou City, comprehensive renovation of the Tongdewei naturally attracted widespread concern in the media and the major media reported it competitively. However, the later established public advisory committees in Guangzhou City, are taking the Tongdewei Public Advisory Committee as the blueprint and become more and more mature, no longer owning significant originality, so the attention of news media are generally decreased. At the same time, the media's pursuing for the "short, adaptable and fast" news will lead to the majority of the media lacking of enough patience to conduct follow-up reports for Committee's work. In such circumstances, the attention of the whole society also will decline.

\section{The Optimization for "Model of the Public Advisory Committee" in Guangzhou's Urban Governance}

The "model of the Public Advisory Committee" provides a direction for the urban governance and reformation in Guangzhou, but the "model of the Public Advisory Committee" is not omnipotent. From the establishment of the Tongdewei Public Advisory Committee to the establishment of other a dozen public committees, connotation of "the Public Advisory Committee" has been expanded and extended. From that the initial public advisory committees are to collect public opinion and reflect the appeal of the masses, to that some latter public consultative committees are to help the government to explain to the public and convince the public, the nature of the Committee is dissimilated. So, how to further improve the Public Advisory Committee and promote reform of urban governance

Firstly, organizational structure of the Public Advisory Committee should be reformed, and its reform should be guided by maintaining the representativeness 
and relative independence of the Public Advisory Committee. This requires that it should be independent from the functional departments, and intervention of the host sector should be diluted as much as possible at the beginning of the establishment of the Committee so as to avoid interference in the interests of the sector and public opinion being "represented" so that the organizational structure and operation of the Committee can be relatively independent, not subordinate to the government, or it can be established in the street offices and other grass-roots organizations. In order to ensure its relative independence, the funds of the Public Advisory Committee should be managed uniformly by the Social Work Committee, which can avoid the Committee being used as a tool for the government from the source.

Secondly, from the reform of operational mechanism, it should be emphasized that the scientificity and democracy of decision-making mechanism. The operational mechanisms of the Committee should be based on the views and recommendations of stakeholders, not the willing of the government. In the process of operating, the issues should be identified by the Public Advisory Committee, which seek to be transparent and enable the Public Advisory Committee to enter the public eye. Only to change the current situation that "many members do not show up, the views formed in the discussion of the Committee members are not open to the public in time, and the public can not reflect the views and demands", let the Public Advisory Committee communicate with the public freely, invite the public to participate in the demonstration and decision-making, it can truly reflect public opinion and win public opinion.

Again, how to ensure the right to know, participation right and right of the supervision of public participation, is the issue the Public Advisory Committee need to pay attention to. In addition to building a good public participation platform to make people effectively participate in the development of normalization and institutionalization of urban governance, we also should unite with multiple forces to co-governance and establish as well as maintain the long-term stability of this partnership (Wang, 2006) [7]. This requires the involvement of the media and personally participation of social elites. In the selection of personnel, the proportion of stakeholders should be increased and the NPC deputies and CPPCC members or prestigious public person and representatives of relevant social organizations should be invited to participate. This multi-participatory approach can help form good and continuous cooperation relations among the government, the social elite and the public. When the interests of all parties conflict, they can be furthest reflected, debated and consulted firstly in the Public Advisory Committee, and the finally the policy accepted by multi parties can be formulated.

Finally, the fundament to ensure the above three aspects is to maintain the initiative of the Public Advisory Committee, which is the only way to achieve the objectives of the Committee. Only to change the situation of "government departments do not want the public to participate in decision-making and not set up the Committee" and realize that citizen participation can be integrated into 
every aspect of the project proposal, executing, supervision and feedback, public power can own real credibility (Jiang \& Zhou, 2004) [8].

\section{Conclusion}

There are both many breakthroughs and puzzles in governance and reform of Guangzhou city. But the successful governance of the Tongdewei shows that the Guangzhou City should seize the opportunity and continue to explore in the system of the Public Advisory Committee, so as to promote the governance and reform of Guangzhou city. At the same time, in the development of a new type of urbanization in Guangzhou city, we should achieve consultative democracy to promote interaction between the government and the public, and realize coordination of good governance.

\section{References}

[1] Sheng, G.Y. (2012) A Review of Studies on Urban Governance. Urban Problems, 10, 81-86.

[2] Yang, J., Zhao, J.Y. and Hu, G. (2015) Reflection of Urban Governance Reform in Guangzhou: A Case of Public Participation in East Hao River Governance. Modern Urban Research, 3, 110-116.

[3] Hu, W. (1998) Process of Government. Zhejiang People's Publishing House, Hangzhou.

[4] Wei, N. (2003) The Mode of Our Urban Community Administration: Development and System Innovation. Journal of Renmin University of China, 1, 135-140.

[5] Amstein, S.R. (1969) A Ladder of Citizen Participation. Journal of the American Institute of Planners, 359, 216-224.

[6] Miller, A.H., Goldenberg, E.N. and Erbring, L (1979) Type-Set Politics: Impact of Newspapers on Public Confidence. The American Political Science Review, 73, 6784. https://doi.org/10.2307/1954731

[7] Wang, D.L. (2006) The Transformation of Urban Management and the Analysis Framework of Urban Governance. Chinese Public Administration, 12, 97-101.

[8] Jiang, J. and Zhou, P.W. (2004) Discussion on Public Participation in Urban Governance. CASS Journal of Political Science, 3, 101-106. 
Submit or recommend next manuscript to SCIRP and we will provide best service for you:

Accepting pre-submission inquiries through Email, Facebook, LinkedIn, Twitter, etc. A wide selection of journals (inclusive of 9 subjects, more than 200 journals)

Providing 24-hour high-quality service

User-friendly online submission system

Fair and swift peer-review system

Efficient typesetting and proofreading procedure

Display of the result of downloads and visits, as well as the number of cited articles Maximum dissemination of your research work

Submit your manuscript at: http://papersubmission.scirp.org/

Or contact jss@scirp.org 